\title{
Using the World Health Organization health system building blocks through survey of healthcare professionals to determine the performance of public healthcare facilities
}

Tsegahun Manyazewal(

\begin{abstract}
Background: Acknowledging the health system strengthening agenda, the World Health Organization (WHO) has formulated a health systems framework that describes health systems in terms of six building blocks. This study aimed to determine the current status of the six WHO health system building blocks in public healthcare facilities in Ethiopia.

Methods: A quantitative, cross-sectional study was conducted in five public hospitals in central Ethiopia which were in a post-reform period. A self-administered, structured questionnaire which covered the WHO's six health system building blocks was used to collect data on healthcare professionals who consented. Data was analyzed using IBM SPSS version 20.

Results: The overall performance of the public hospitals was $60 \%$ when weighed against the WHO building blocks which, in this procedure, needed a minimum of $80 \%$ score. For each building block, performance scores were: information 53\%, health workforce 55\%, medical products and technologies 58\%, leadership and governance $61 \%$, healthcare financing $62 \%$, and service delivery $69 \%$. There existed a significant difference in performance among the hospitals $(p<.001)$.

Conclusion: The study proved that the WHO's health system building blocks are useful for assessing the process of strengthening health systems in Ethiopia. The six blocks allow identifying different improvement opportunities in each one of the hospitals. There was no contradiction between the indicators of the WHO building blocks and the health sustainable development goal (SDG) objectives. However, such SDG objectives should not be a substitute for strategies to strengthen health systems.
\end{abstract}

Keywords: World Health Organization, Health system, Health system strengthening, Health development goals, Ethiopia

\section{Background}

The 2016 transition in global health from Millennium Development Goals (MDGs) to Sustainable Development Goals (SDGs) is a remarkable move for resource-limited countries that have been struggling to improve the quality of healthcare at the ground [1-4]. The various MDG targets for health were instrumental in shaping healthcare outcomes; with a

Correspondence: tsegahunm@gmail.com

Department of Health Studies, College of Human Science, University of

South Africa, Pretoria P.O. BOX 392, South Africa significant number of resource-limited countries able to meet the targets $[5,6]$. Similarly, it is worthy that these countries have given increased attention to the current SDGs for health. However, fulfillment of global health targets, unaided by the overall health system strengthening efforts which is mainly a national issue [7], does not guarantee improvement of the overall health system [8-10].

Acknowledging the health system strengthening agenda, the World Health Organization (WHO) has formulated a health systems framework that describes 
health systems in terms of six building blocks which include service delivery, health workforce, information, medical products, vaccines and technologies, financing, and leadership/governance (Fig. 1) [11]. Good service deliveries are those which deliver effective, safe, quality personal and non-personal health interventions to those that need them, when and where needed, with minimum waste of resources. A well-performing health workforce is one that works in responsive ways, fair and efficient to achieve the best health outcomes possible, given available resources and circumstances. A well-functioning health information system is one that ensures the production, analysis, dissemination and use of reliable and timely information on health determinants, health system performance and health status. A well-functioning health system ensures equitable access to essential medical products, vaccines and technologies of assured quality, safety, efficacy and cost-effectiveness, with scientifically sound and cost-effective use. A good health financing system raises adequate funds for health, in ways that ensure people can use needed services and are protected from financial catastrophe or impoverishment associated with having to pay for them. Leadership and governance involve ensuring the existence of policy frameworks combined with effective oversight, coalition building, regulation, attention to system design and accountability. Strengthening health system means improving these six health system building blocks and managing their interactions in ways that achieve more equitable and sustained improvements across health services and health outcomes which require technical and political knowledge and action [11]. The WHO has supported its health system framework with a monitoring and evaluation framework to monitor program management of health system investments, assess health system performance and evaluate the results of health reform investments [12].

Studies indicate the WHO health system framework is instrumental in strengthening the overall health system and uses as catalyst for achieving global health targets such as the SDGs. Unlike other health system strengthening strategies which are disease-specific [13] or narrow [14-16], the WHO's health system framework intends to improve the overall health in a responsive, financially fair and most efficient way [11]. Evidences revealed that the framework helps to assess in-country healthcare performances [17], interactions between health reforms and country health systems [18], implications of health sector reforms [19], and the status of health facilities [20] and specific health problems [21].

The various global health development goals and commitments have been the alarm bells to the government of Ethiopia. With significant contributions from global partners, the government of Ethiopia tailored to meet many of the global health indicators. For instance, the country has successfully achieved six of the eight MDGs, including MDG Goal 4 and other targets for HIV/AIDs, malaria, tuberculosis and other diseases, while MDG 5 (improve maternal health) is an area the country was off-track [22]. However, meeting such global targets alone could not justify improved and sustainable health system and the readiness responding effectively to unanticipated health threats.

Since 2008, the Ethiopian government is implementing healthcare reform aimed at strengthening the overall health system [23]. A system of tracking clients' opinions and complaints about services has been put in place to enable the Ethiopian government to take appropriate and immediate actions. Based on the principle of BPR

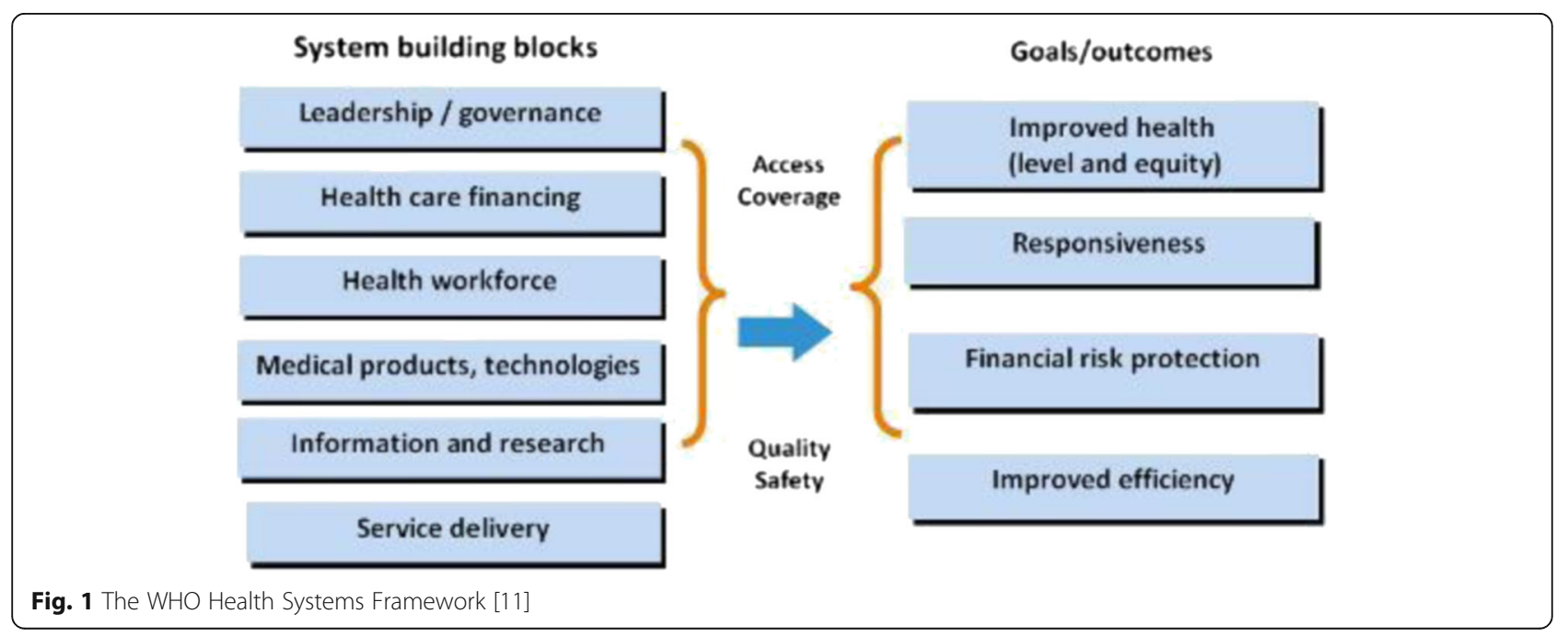


[24], the FMoH has conducted "as is" analysis to document pertinent issues, understand the pros and cons of the existing healthcare delivery system in the country and figure out the different dynamics that should be considered in the redesign of the new reform. With these, "to be" business processes were designed, public health sector standards formulated, and standard operating procedures and implementation tools developed [25]. The reform has been progressively implemented through a series of training sessions for managers and technicians at all levels followed by changes in staff deployment, specific job assignments and the recruitment of new staff. Stretched objectives were synthesized and sub processes that form the core process identified. Public hospital services were structured into three major case teams namely; Emergency, Outpatient, and Inpatient, where Outpatient and Inpatient case teams were further classified into eight and nine case teams, respectively [26]. However, despite implementing the healthcare in public healthcare facilities, little is known about the current status of the public hospitals in terms of the WHO's health system building blocks.

Building on the lessons learned in the MDGs and considering the current socioeconomic landscape, the Government of Ethiopia is developing and implementing its Health Sector Transformation Plan (HSTP) - a fiveyear (2015-2020) national health sector strategic plan and the first phase in the 'Envisioning Ethiopia's Path towards Universal Health Coverage through Strengthening Primary Healthcare' [22]. In the HSTP, four pillars of excellence are believed to help the sector attain its mission and vision: health service delivery, quality improvement and assurance, leadership and governance, and health system capacity. The four pillars are linked with the WHO's six health system building blocks.

The status of the WHO's six building blocks at public health facilities would configure the health system and its outcomes in national as well as global needs. Public hospitals, with their possibilities for improved healthcare services, training, research and innovations, are potential to favorably influence the broader array of the healthcare system. Thus, periodic evaluation of the overall healthcare system is required to identify gaps and provide appropriate interventions. Such constructive insights would consolidate global health development goals and routine healthcare needs for possible improvements of the overall health system. Keeping this up-front, this study intends to determine the current status of the WHO's six health system building blocks in public hospitals in central Ethiopia.

\section{Methods}

A quantitative, cross-sectional study was carried out to analyze the status of the Six WHO health system building blocks in public hospitals in central Ethiopia, thus Addis Ababa. Addis Ababa was selected among the 11 administrative divisions of Ethiopia considering its presence as the largest and city capital of Ethiopia. The Addis Ababa Health Bureau has been implementing the healthcare reform in public healthcare sector that it owned. The bureau administers six public hospitals which deliver advanced preventive and curative health services, from which all that have been implementing the BPR healthcare reform since its inception in $2009(n=5)$ were purposively selected to maximize the scope of the study thereby ensure external validity. Hence, the five public hospitals were purposively sourced as they were in a post-reform phase.

The study was conducted between January and June 2015. The target group was all healthcare professionals in the public hospitals $(n=1681)$ which included medical doctors, nurses, laboratory professionals, pharmacists, dentists, health officers, and sanitarians. Of these, all who started working in the hospitals at least a year ahead of initiation of the reform $(n=476,28 \%)$ were purposively drawn to select respondents who knew the performance of the hospitals before implementation of the reform and better analyze the changes that occurred because of the reform.

A self-administered, structured questionnaire targeting healthcare professionals was developed in a 5-level scale and used for data collection. To elicit a quality questionnaire, secondary data and related studies conduct elsewhere were reviewed and the questionnaire pretested. The questionnaire was structured to cover the six WHO health system building blocks and specific indicators were adapted from the target in the BPR healthcare reform document for improvements in healthcare facilities:

Leadership/governance: new organizational practices and policies, the best use of resources, appropriate use of staff working hour, satisfaction of patients and providers, capacity to assemble and manage resources; Healthcare financing: efficient and effective healthcare financing system, linkage of financial mobilization with evidence-based plan, effective budget consumption, the required financial resources to ensure sustainability, and reduced wastage and enhanced cost-effective interventions; Health workforce: qualified staff, job satisfaction, motivation, conducive structure, appropriate and timely feedback;

Medical products/technologies: adequate drugs, medical supplies, medical apparatuses and equipment, up-todate technologies for patient diagnosis, new organizational practices and policies, networking with the external environment; 
Information: monitoring and evaluation, up-to-date and appropriate guidelines and protocols, appropriate internet access, easy and time-efficient reporting system; Service delivery: patient satisfaction, on-time services, improved treatment and respect to patients, patient indiscrimination, mode of communications suitable to patients.

Data analysis was performed through calculation of descriptive statistical procedures on IBM SPSS version 20. Each of the five responses had a numerical value (1-5), in which the highest two scoring answers (4 and 5) were taken as positive outcomes while the rest three responses were considered as negative outcomes. With this, a positive outcome for each of the WHO six building blocks had a value of 4 , which is equivalent to a mean percentage score [27] of $80 \%$ or above. As the questions were grouped under the six building blocks, a scale score was computed as the mean of the scale item scores, while the median score was employed to measure central tendency among individual questions.

The study was granted ethical clearance certificate from the Higher Degrees Committee of the Department of Health Studies, University of South Africa and the Research and Technology Transfer Core-process of the Addis Ababa City Administration Health Bureau. Informed consent form was developed for each respondent to read and sign before moving on to fill-in the questionnaires.

\section{Results}

\section{Socio-demographic profile}

A total of 406 healthcare professionals participated in the study, among which $282(69.5 \%)$ were women. The majority of participants $(195,48 \%)$ were in the age ranging from 30 to 39 , while very few $(26,6.4 \%)$ were in the age ranging from 50 to 59 . The largest proportion of participants $(304,74.9 \%)$ was nurses, followed by medical doctors $(35,8.6 \%)$, medical laboratory professionals (24, 5.9\%), pharmacist (16, 3.9\%), X-ray technicians (11, $2.7 \%)$ and sanitarians (2, 0.5\%). Academically, the largest proportion of participants $(342,84.2 \%)$ had bachelor's degree, followed by Diploma (37, 9.1\%), medical doctorate with specialization (18, 4.4\%), MSc/MA or MPH (7, $1.7 \%)$, and certificate $2(0.5 \%)$. A large number of participants $(202,49.8 \%)$ worked as a healthcare professional for 10 to 19 years.

Table 1 summarizes the status of the WHO six building blocks in the study hospitals.

\section{Leadership/governance building block}

Data was collected about elements of governance/leadership from public healthcare perspectives. Given the increasing diffusion of new organizational practices and policies across the study hospitals, the impact of this practice had little benefit (60\%) when weighed against the perceived value $(\geq 80 \%)$. Resource management had challenges in that the best use of resource (65\%) and the capacity to assemble and manage resources (61\%) in the hospitals were not adequate, signifying that leadership skills were loosen on this matter. Regarding staff working hour, the result was smaller (58\%) and even lesser than all the rest scores in leadership/governance section, implying a higher misuse of working hours in the hospitals. Healthcare professionals in the hospitals perceive an overall $61 \%$ satisfaction of employees and patients regarding how the hospitals are currently operating. In this leadership/governance category, a relatively highest score (65\%) was in the use of resources, while the least score (58\%) was in the use of staff working hours. In general, the average score of leadership/governance in this study was $61 \%$, which was lower than the $80 \%$ score perceived in the WHO's health system framework.

\section{Healthcare financing}

For this building block, five questions were posed to realize the healthcare financing capacity of the hospitals. The author learned from the healthcare professionals that there is a loosen linkage between financial mobilization and evidence-based planning. The performance of the hospitals toward reducing wastage of resources while enhancing cost-effective interventions was deprived and the overall budget consumption was ineffective, which were potential for financial recessions. There had been a relatively better achievement (65\%) towards gaining financial resources essential for sustainability of healthcare services. The average score of leadership/governance was $62 \%$, which was yet lower than the perceived $80 \%$ score.

\section{Health workforce}

This section witnessed multifactorial public health workforce challenges which need contextual changes in line with the WHO health workforce needs. The study captures major claims on availability of staff restrooms (47\%). There exist job dissatisfaction and demotivation of the public health workforce, with potential impacts on the overall health system. The average score for health workforce was $55 \%$, which was much lower than the $80 \%$ score perceived for the WHO's health system framework for health workforce.

\section{Medical products/technologies}

The impetus for medical technologies and practices had gaps when scaled against the intended WHO requirements. The hospitals are not well-resourced with enough 
Table 1 The status of the WHO health system building blocks in public hospitals

\begin{tabular}{|c|c|}
\hline WHO health system building blocks & Score (\%) \\
\hline \multicolumn{2}{|l|}{ Leadership/Governance } \\
\hline New organizational practices and policies & 60 \\
\hline The best use of resources & 65 \\
\hline Appropriate use of staff working hour & 58 \\
\hline Satisfaction of patients and providers & 61 \\
\hline Capacity to assemble and manage resources & 61 \\
\hline Average & 61 \\
\hline \multicolumn{2}{|l|}{ Healthcare financing } \\
\hline Efficient and effective health care financing system & 63 \\
\hline $\begin{array}{l}\text { Linkage of financial mobilization with } \\
\text { evidence-based plan }\end{array}$ & 58 \\
\hline Effective budget consumption & 62 \\
\hline $\begin{array}{l}\text { The required financial resources to insure } \\
\text { sustainability }\end{array}$ & 65 \\
\hline $\begin{array}{l}\text { Reduced wastage and enhanced } \\
\text { cost-effective interventions }\end{array}$ & 61 \\
\hline Average & 62 \\
\hline \multicolumn{2}{|l|}{ Health workforce } \\
\hline The required qualified staff & 63 \\
\hline Job satisfied staff & 51 \\
\hline Motivated staff & 49 \\
\hline Conducive staff rest room & 47 \\
\hline Conducive structure & 62 \\
\hline Appropriate and timey feedback & 56 \\
\hline Average & 55 \\
\hline \multicolumn{2}{|l|}{ Medical technology } \\
\hline $\begin{array}{l}\text { Enough drugs, medical supplies, medical } \\
\text { apparatuses and equipment }\end{array}$ & 56 \\
\hline Up-to-date technologies for patient diagnosis & 58 \\
\hline New organizational practices and policies & 56 \\
\hline Networking with external environment & 60 \\
\hline Average & 58 \\
\hline \multicolumn{2}{|l|}{ Information } \\
\hline Monitoring and evaluation system & 64 \\
\hline Up-to-date and appropriate guidelines and protocols & 57 \\
\hline Internet access & 38 \\
\hline Easy and time-efficient reporting system & 53 \\
\hline Average & 53 \\
\hline \multicolumn{2}{|l|}{ Service delivery } \\
\hline Satisfied patients & 63 \\
\hline On-time services & 69 \\
\hline Improved treatment and respect to patients & 66 \\
\hline No patient discrimination & 80 \\
\hline $\begin{array}{l}\text { Services to patients using mode of communication } \\
\text { suitable to patients }\end{array}$ & 69 \\
\hline Average & 69 \\
\hline
\end{tabular}

drugs, medical supplies, medical apparatus and equipment. As well, there was a need for networking the hospitals with the external environment for a possible exchange of medical technologies. The average score of medical technologies was 58\%, which was much lower than the $80 \%$ score intended in the WHO's health system framework for medical products/technologies.

\section{Information}

The study set out to the existing information system in terms of the WHO building block and found that information is limited in opportunity and scope. Healthcare professionals in the hospitals recognized that access to internet is limited (38\%) to hospital staff. The hospitals' duties were poorly supported by up-to-date and appropriate guidelines and protocols. Monitoring and evaluation system of the hospitals was viewed as a fairly practice when compared with other responses in this section. The average score for information was 53\%, which was much lower than the intended $80 \%$ score.

\section{Service delivery}

Service delivery had some fairly gains. The healthcare professionals $(80 \%)$ highlighted that there are no patient discriminations, though this finding needs to be confirmed with patients. On-time access to services and availability of services in a mode of communication suitable to patients both scored $69 \%$. The average score for service delivery was $69 \%$, which was yet lower than the perceived $80 \%$ and above score. While this $69 \%$ score for service delivery was the highest among the six WHO health system building blocks.

\section{Overall performance}

In line with the WHO health system building blocks, the overall health system performance of public hospitals in central Ethiopia was 60\%. Looking at each building block, results were lesser for information (53\%), health workforce (55\%), medical products/technologies (58\%), leadership/governance (61\%), healthcare financing (62\%) and service delivery (69\%). There was a significant difference in healthcare performance between at least two hospitals $\left(x^{2}=571.902, p<.001\right)$.

\section{Discussion}

This study aimed to find out the current status of the six WHO health system building blocks in public healthcare facilities in Ethiopia. The findings revealed that the overall performance of public hospitals which were in a post-reform phase was lesser when weighed against the WHO's six health system building blocks. The public hospitals scored less for each WHO building block, which includes information, health workforce, medical 
products/technologies, leadership/governance, healthcare financing, and service delivery.

Over the past decade, the WHO and other organizations in the field have given much attention to the issue of health systems strengthening [7, 14, 28-30] and the government of Ethiopia has been in the loop reaffirming its commitments and consolidating the gains $[10,13$, 31-33]. This study deepens understanding of how healthcare facilities can develop a platform to assess and monitor their performances for on-going improvements in the context of the WHO's six health system building blocks. The approach facilitates results measurement through generating data for measuring outputs for a better and sustained improvement. The main data source of the study was from healthcare professionals which are the ultimate resources of health systems and markedly responsible for monitoring the healthcare climate [34]. Studies exhibited that healthcare professionals are key sources of information to track and monitor health system progresses $[35,36]$, and there have been unwanted variations in healthcare practices that cannot be explained by patients [37].

The study witnessed that there were major issues which may affect the status of the six WHO building blocks in public hospitals. The hospitals' governances did not pursue staff loyalty to effectively use their time to maximize the hospitals' capacity and sustainability. This needs keener interest of the hospitals' administrations to probe on the governance constraints and take possible interventions to attain the intended WHO governance/leadership needs among others.

Healthcare financing was another concern in the current status of the WHO building blocks. The healthcare financing capacity, in relation to healthcare goods and services, indicates that mandatory steps still remain. The hospitals were not effective enough in linking financial mobilization with evidence-based plans. Besides, the hospitals were unable to reduce wastages and enhance cost-effective interventions. These indicate that the healthcare financing gaps identified in this study need to restructure. The policy options that the $\mathrm{FMoH}$ proposed to address challenges in healthcare financing are health insurance and social health insurance [38]. These two options could be considered as possible options for improvement in healthcare financing. However, additional specific strategies which target public hospitals need to be formulated to address finance related gaps identified in the study. As households in rural part of Ethiopia are included in public health insurance schemes [39], the Ethiopian government could shift existing budgets for strengthening health system at public hospitals. The cost which was estimated for implementing the HSTP in the year $2015 / 16-2019 / 20$ is $\$ 177,723,169$, where the highest share goes to human resource and infrastructure
[22]. From this budget, public hospitals need to secure a significant share to enhance their capacity and be equipped with innovative technologies.

Regarding health workforce, only a fraction of the WHO building block for workforce was achieved. Lack of job satisfaction, motivation, convenient infrastructure, timely performance feedback, and qualified staff were major gaps identified in the public hospitals. This finding is in support of previous studies conducted in Ethiopia at different times and with different target populations [40-43]. A previous report of the $\mathrm{FMoH}$ also witnessed scarcity and inappropriate usage of medical products and technologies in public hospitals [22]. There were scarcities of drugs, medical supplies, medical apparatus, and equipment in the hospitals. There was less effort taken towards initiating new practices for effective and advanced usage of technologies. Hence, evocative strategies with huge investments in health workforces' education and training, management, retention, incentives, motivation, and job satisfaction are required to meet the intended human resource need.

Similarly, information communication and exchange methods, which are active catalysts in the broadbased health development, were stagnated, thus need improvements. The hospitals have been highly affected by lack of sufficient internet access in the hospitals, which could hinder staff from updating their knowledge and translating to their patients. In the same sense, there have been many guidelines that the $\mathrm{FMoH}$ and its partner organizations developed and shared for bench-level use. However, the guidelines and other standard operating procedures were not fairly in place as quick references. Such constraints need practicable health information strategies coupled with monitoring system. Overall, there is a need for further progress in all the six WHO health system building blocks. The use of the six WHO health system building blocks was proved to be instrumental for assessing and following-up of the overall healthcare system.

This study is with some limitations. Evidences only from healthcare professionals might be subjected to their experiences and expectations. Hence, expanding the sources of the study data set to capture more inclusive information that could be obtained from patients or the existing hospital data was necessary. On the other side, the relatively low proportion of physicians among those who answered the interview may hide the actual view of clinicians in the analysis. Or else, the study's approach proved that the use of the six WHO building blocks to numerically assess and monitor public healthcare sectors is possible. Healthcare facilities can employ this approach to 
assess and follow-up their own strengths and weaknesses with minimum costs. With this, it is possible to strengthen health system at various levels, and simultaneously integrate global health commitments for sustainability and ownership.

\section{Conclusion}

The study proved that the WHO's six health system building blocks are useful for assessing the process of strengthening health systems in Ethiopia. The six blocks allow identifying different improvement opportunities in each one of the hospitals. There is no contradiction between the indicators of the WHO health systems building blocks and the health sustainable development goal (SDG) objectives. However, such SDG objectives should not be a substitute for strategies to strengthen health systems.

\section{Abbreviations}

FMoH: Federal Democratic Republic of Ethiopia Ministry of Health; HSTP: Health Sector Transformation Plan; MDG: Millennium Development Goal; SDG: Sustainable Development Goal; WHO: World Health Organization

\section{Acknowledgments}

The author would like to thank Prof. MC Matlakala, Prof. MJ Oosthuizen, and Dr. Shewangizaw Getahun for their expert guidance.

\section{Funding}

This research project has been supported by the University of South Africa.

\section{Availability of data and materials}

The dataset supporting the conclusions of this article is included within the article.

\section{Authors' contributions}

TM conceived, designed and implemented the study. TM analysed and interpreted data, wrote the first draft, critically revised it for important intellectual content and approved the final version of the manuscript for publication.

\section{Ethics approval and consent to participate}

The study was granted an ethical clearance certificate from the Higher Degrees Committee of the Department of Health Studies, University of South Africa, and the Research and Technology Transfer Core-process of the Addis Ababa City Administration Health Bureau.

Written informed consent was developed for each respondent to read and sign before moving on to fill-in the questionnaire.

\section{Consent for publication}

The study did not include details, images, or videos relating to individual participants, thus consent for publications were not required.

\section{Competing interests}

The author declares that she has no competing interests.

\section{Publisher's Note}

Springer Nature remains neutral with regard to jurisdictional claims in published maps and institutional affiliations.

Received: 24 March 2017 Accepted: 12 July 2017

Published online: 31 August 2017

\section{References}

1. Liu L, Oza S, Hogan D, Chu Y, Perin J, Zhu J, et al. Global, regional, and national causes of under-5 mortality in 2000-15: an updated systematic analysis with implications for the sustainable development goals. Lancet. 2017;388(10063):3027-35.

2. Fowkes FJ, Draper BL, Hellard M, Stoové M. Achieving development goals for HIV, tuberculosis and malaria in sub-Saharan Africa through integrated antenatal care: barriers and challenges. BMC Med. 2016;14(1):202.

3. Bundhamcharoen K, Limwattananon S, Kusreesakul K, Tangcharoensathien $V$. Contributions of national and global health estimates to monitoring health-related sustainable development goals. Glob Health Action. 2016;9:32443.

4. Tebbutt E, Brodmann R, Borg J, MacLachlan M, Khasnabis C, Horvath R. Assistive products and the sustainable development goals (SDGs). Glob Health. 2016;12(1):79.

5. GBD 2015 SDG Collaborators. Measuring the health-related Sustainable Development Goals in 188 countries: a baseline analysis from the Global Burden of Disease Study 2015. Lancet. 2016:388(10053):1813-50.

6. Kirigia JM, Pannenborg CO, Amore LG, Ghannem H, IJsselmuiden C, Nabyonga-Orem J. Global forum 2015 dialogue on "from evidence to policy - thinking outside the box": perspectives to improve evidence uptake and good practices in the African region. BMC Health Serv Res. 2016;16(4):215.

7. Hafner T, Shiffman J. The emergence of global attention to health systems strengthening. Health Policy Plan. 2013;28(1):41-50.

8. Chapman AR. Assessing the universal health coverage target in the sustainable development goals from a human rights perspective. BMC Int Health Hum Rights. 2016;16(1):33

9. Mann C, Ng C, Akseer N, Bhutta ZA, Borghi J, Colbourn T, et al. Countdown to 2015 country case studies: what can analysis of national health financing contribute to understanding MDG 4 and 5 progress? BMC Public Health. 2016;16(2):792.

10. Manyazewal T, Oosthuizen MJ, Matlakala MC. Proposing evidence-based strategies to strengthen implementation of healthcare reform in resourcelimited settings: a summative analysis. BMJ Open. 2016;6(9):e012582.

11. World Health Organization (WHO). Everybody's business - strengthening health systems to improve health outcomes: WHO's framework for action. WHO; Geneva: 2007. http://www.who.int/healthsystems/strategy/ everybodys_business.pdf

12. World Health Organization (WHO). Monitoring the building blocks of health systems: a handbook of indicators and their measurement strategies. Geneva, Switzerland: WHO;2010.

13. Marinucci F, Manyazewal T, Paterniti AD, Medina-Moreno S, Wattleworth M, Hagembe J, et al. Impact of horizontal approach in vertical program: continuous quality improvement of malaria and tuberculosis diagnostic services at primary-level medical laboratories in the context of HIV care and treatment program in Ethiopia. Am J Trop Med Hyg. 2013;88(3):547-51.

14. Swanson RC, Atun R, Best A, Betigeri A, de Campos F, Chunharas S, et al. Strengthening health systems in low-income countries by enhancing organizational capacities and improving institutions. Glob Health. 2015;11:5.

15. Goldberg J, Bryant M. Country ownership and capacity building: the next buzzwords in health systems strengthening or a truly new approach to development? BMC Public Health. 2012:12:531.

16. van Olmen J, Marchal B, Van Damme W, Kegels G, Hill PS. Health systems frameworks in their political context: framing divergent agendas. BMC Public Health. 2012;12:774

17. Mounier-Jack S, Griffiths UK, Closser S, Burchett H, Marchal B. Measuring the health systems impact of disease control programmes: a critical reflection on the WHO building blocks framework. BMC Public Health. 2014:14:278.

18. Senkubuge F, Modisenyane M, Bishaw T. 2014. Strengthening health systems by health sector reforms. Glob health action. 2014:7:23568.

19. Obermann K, Chanturidze T, Richardson E, Tanirbergenov S, Shoranov M, Nurgozhaev A. Data for development in health: a case study and monitoring framework from Kazakhstan. BMJ Global Health. 2016;1:e000003.

20. Mutale W, Bond V, Mwanamwenge MT, Mlewa S, Balabanova D, Spicer N, et al. Systems thinking in practice: the current status of the six WHO building blocks for health system strengthening in three BHOMA intervention districts of Zambia: a baseline qualitative study. BMC Health Serv Res. 2013; 13:291

21. Fisher JR, Cabral de Mello M. Using the World Health Organization's 4SFramework to Strengthen National Strategies, Policies and Services to Address Mental Health Problems in Adolescents in Resource-Constrained Settings. Int J Ment Health Syst. 2011;5:23.

22. Federal Democratic Republic of Ethiopia Ministry of Health ( $\mathrm{FMoH})$. Health Sector Transformation Plan (HSTP): 2015/16-2019/20. Addis Ababa, Ethiopia: 
FMoH; 2015. http://globalfinancingfacility.org/sites/gff_new/files/ documents/HSTP\%20Ethiopia.pdf

23. Federal Democratic Republic of Ethiopia Ministry of Health (FMoH). 2010 Health Sector Development Program IV, 2010/11-2014/14. FMOH Addis Ababa; Ethiopia http://www.nationalplanningcycles.org/sites/default/files/ country_docs/Ethiopia/ethiopia_hsdp_iv_final_draft_2010_-2015.pdf

24. Sturdy GR. Business Process Reengineering: Strategies for Occupational Health and Safety. Cambridge Scholars Publishing 2010. Newcastle, United Kingdom http://www.cambridgescholars.com/download/sample/58104

25. Federal Democratic Republic of Ethiopia Ministry of Health (FMoH). Standards for access and quality of health service. FMoH 2007. Addis Ababa, Ethiopia.

26. Adds Ababa City Government Health Bureau (AAHB). Standard operation procedure for the delivery of medical services. AAHB curative services core process 2008. Addis Ababa, Ethiopia.

27. Warner RM. Applied statistics: from bivariate through multivariate techniques. 2nd ed. USA: SAGE Publications, Inc; 2013.

28. Shakarishvili G, Lansang MA, Mitta V, Bornemisza O, Blakley M, Kley N, et al. Health systems strengthening: a common classification and framework for investment analysis. Health Policy Plan. 2011;26(4):316-26.

29. Frenk J. The global health system: strengthening national health systems as the next step for global progress. PLoS Med. 2010;7(1):e1000089.

30. Moon S. WHO's role in the global health system: what can be learned from global R\&D debates? Public Health. 2014;128(2):167-72.

31. McNatt Z, Linnander E, Endeshaw A, Tatek D, Conteh D, Bradley EH. A national system for monitoring the performance of hospitals in Ethiopia. Bull World Health Organ. 2015;93(10):719-26.

32. Busse $\mathrm{H}$, Aboneh $\mathrm{EA}$, Tefera $\mathrm{G}$. Learning from developing countries in strengthening health systems: an evaluation of personal and professional impact among global health volunteers at Addis Ababa University's Tikur Anbessa Specialized Hospital (Ethiopia). Glob Health. 2014;10:64.

33. Wispelway BP. Rethinking responsibility in global health: a case from Ethiopia. Social Medicine in Practice. 2016;9(3):129-31.

34. Manyazewal T, Matlakala MC. Beyond patient care: the impact of healthcare reform on job satisfaction in the Ethiopian public healthcare sector. Human Resource for Health. 2017;15:10.

35. Olukoga A, Bachmann M, Harris G, Olukoga T, Oluwadiya K. Analysis of the perception of institutional function for health sector reform in Nigeria. International Health. 2010;2(2):150-5.

36. Ganjian S, Dowling PT, Hove J, Moreno G. What physicians from diverse specialties know and support in health care reform. Fam Med. 2015; 47(4):283-91.

37. Flottorp SA, Jamtvedt G, Gibis B, McKee M. Using audit and feedback to health professionals to improve the quality and safety of health care. World Health Organization, on behalf of the European Observatory on Health Systems and Policies. Copenhagen, Denmark; 2010

38. Ethiopian Public Health Institute (EPHI). Improving health care financing in Ethiopia: an evidence brief for policy. Addis Ababa, Ethiopia: EPHI; 2014

39. Kebede A, Gebreslassie M, Yitayal M. Willingness to pay for community based health insurance among households in the rural community of Fogera District, north West Ethiopia. International Journal of Economics, Finance and Management Sciences. 2014;2(4):263-9.

40. Engeda EH, Birhanu AM, Alene KA. Intent to stay in the nursing profession and associated factors among nurses working in Amhara regional state referral hospitals. Ethiopia BMC Nursing. 2014;13(24):1-8.

41. Negussie N. Relationship between rewards and nurses' work motivation in Addis Ababa hospitals. Ethiopian Journal of Health Science. 2012;22(2):107-12

42. Yami A, Hamza L, Hassen A, Jira C, Sudhakar M. Job satisfaction and its determinants among health workers in Jimma university specialized hospital, southwest Ethiopia. Ethiopian Journal of Health Science. 2011;21:19-27.

43. Assefa F, Mosse A, H/Michael Y. Assessment of client satisfaction with health service deliveries at Jimma university teaching hospital. Ethiopian Journal of Health Science. 2012;21(2):101-9.

\section{Submit your next manuscript to BioMed Central and we will help you at every step:}

- We accept pre-submission inquiries

- Our selector tool helps you to find the most relevant journal

- We provide round the clock customer support

- Convenient online submission

- Thorough peer review

- Inclusion in PubMed and all major indexing services

- Maximum visibility for your research

Submit your manuscript at www.biomedcentral.com/submit

) Biomed Central 